\title{
The 4 phases of evolution of political communication systems: from the golden age of the parties to the golden age of the
}

\section{users}

\author{
Assist. Prof. PhD. Tănase Tasențe \\ “Ovidius" University of Constanta, Romania \\ office@pluscommunication.eu
}

\begin{abstract}
The political media communication system began to develop, in a first phase, in the first two decades after the Second World War, this period being called by Blumler and Kavanagh (1999) as "the golden age of the parties" or as "the age of the newspapers". In the 1960s, a new stage in the evolution of political communication systems began, when few national televisions put a monopoly on the media market, becoming the dominant medium in which political communication unfolded. This stage was named "the television era" or "the modern period of electoral campaigns". Two new aspects to the previous period of evolution are due to the diminution of the voters' loyalty and trust towards the political parties and the shift from direct communication to prime-time communication. The third phase of the evolution of political communication systems began to take shape at the end of the 20th century and the beginning of the 21 st century and was called the "postmodern period" or "digital era". Major changes in this period of political communication development have occurred both in technology, consumer behavior of voters, and in communication strategies. After 1990, for many other democratic countries and after 2000, for other totalitarian countries, political communication has undergone a strong transformation into its three points: (1) changing the communication channel and its characteristics far different from classical means, (2) related to the content of the message and the political discourse and, perhaps, the most important aspect (3) the public's ability to actively participate in government acts or protest actions challenging government acts.
\end{abstract}

Keywords. political communication, television era, newspaper era, digital era, social media era 


\section{Introduction}

Scholars have identified a series of relationships between profound changes in society and the media in the mass and the emergence of a new form of political communication system, which differentiates in quantitative, but above all qualitative sense, from the previous system. In this sense, the channels of transmission of political messages not only multiply, but they become diverse, much more fragmented and complex than the previous evolutionary stage. Also, at a much deeper level, the power and influence relationships between key message providers and recipients have been reorganized: both the culture of political journalism has changed significantly and the conventional definitions of "democracy" and "citizenship" were rethought. Moreover, operational concepts such as "e-democracy", "e-politics", "e-government" appeared on online platforms whereby the beneficiaries of the government, ie citizens, can actively engage with the governors to debate and even to impose public policies. This last phase of evolution of political communication systems, centered on the online environment, is also our research object. Until then, we will have to review the other phases of evolution of political communication systems, identify the peculiarities of each and determine what the novelties of the current evolutionary phase have been. Regarding these major changes in the mechanisms and channels of communication in the political sphere, two British researchers, Jay Blumer and Dennis Kavanagh, distinguish three phases of the evolution of political communication systems that can be found in many democratic states. Each of these phases was based on different organizational principles and was called "phase no. 1", "phase no. 2" and "phase no. 3" evolution of political communication systems. The 4th phase of development is underway since the first social media campaigns took place in the United States in 2008, and since then, this phenomenon has become a must-have for any political party, not just in the electoral campaign, but also in the political campaign.

The first phase of the evolution of political communication systems: the age of the newspapers

The political media communication system began to develop, in a first phase, in the first two decades after the Second World War, this period being called by Blumler and Kavanagh (1999) as "the golden age of the parties" or as "the age of the newspapers".

Thanks to multiple initiatives and debates on social reforms, the political system enjoys credibility among public opinion. Political parties were built on the discrepancies in the political orientation of social structures, and the electorate was referring to politics through the identification of more or less the brand or doctrine of traditional parties. Political communication was built on the basis of 


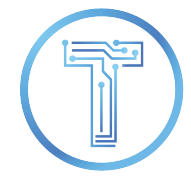

consensus between politicians and their electorate, consensus based on a favorable reputation of political institutions. The voting decision was based in most cases on sympathy and loyalty to a particular political party, the electorate was a stable one, and an option already formed was very difficult if not impossible to change.

Jay Blumer and Dennis Kavanagh (1999) identified three basic characteristics of the communication system in the first phase of evolution, a system based on party domination, as follows:

(1) the majority of political messages had substance; politicians built their political speeches centered on issues that matter to them and the citizens, the major changes they want to make in the governing act, and the principles and policies that define their political doctrine and which differentiate them from their political opponents.

(2) many such political messages have enjoyed relatively large access to the media at that time; the stream of political communication was more pro than against the principle of political partisanship;

(3) many voters responded appropriately to political messages through selectivity and reinforcement. Another important feature of this evolutionary era is the importance of local campaigning, the central role of parties in electoral communication, and this communication is carried out directly through door-to-door propaganda.

The second phase of the evolution of political communication systems: the age of the television

In the 1960s, a new stage in the evolution of political communication systems began, when few national televisions put a monopoly on the media market, becoming the dominant medium in which political communication unfolded. This stage was named "the television era" or "the modern period of electoral campaigns". Two new aspects to the previous period of evolution are due to the diminution of the voters' loyalty and trust towards the political parties and the shift from direct communication to prime-time communication.

Thus, a series of four transformations appeared, which researchers Blumer and Kavanagh (1999) highlighted as follows:

(1) reducing the selectivity of information sources as a result of the decline in written press. Equidistant news began to be broadcast, the information being documented from several sources. Also, broadcast time were allocated to most parties, which meant that the public did not have to go through more information sources to find party views because they could be found in a single source. 
(2) the main channel of political debate has become television, where norms have been introduced to remove partisan attitudes of journalists and to promote fairness, impartiality and neutrality. Channels of communication that respected these principles have become central platforms for political communication. Over time, political partisans have diminished, legitimating the attitude that engagement conditioned by party performance and prudence has become an appropriate attitude for a model citizen.

(3) Televisions have expanded the audience of political communication campaigns by reaching more difficult-to-reach public segments such as women or young people.

(4) TV news has become the means of communication with the greatest communication impact in the short term, favoring the development of strategies for influencing the media agenda.

The rise of television as the main means of transmitting political messages has generated some new effects - both positive and negative - that have opened the way for professionalisation of political and electoral communication. First, the election campaigns began to be organized and coordinated by party leaders, and behind all communication strategies were communication specialists in the study of public opinion and consultants from outside the party. The negative effect was that the televisions caused the campaigners to distance themselves from the electoral audience, becoming more passive in the electoral process, and the loyalty to the parties declined considerably.

\section{The third phase of the evolution of political communication systems: digital era}

The third phase of the evolution of political communication systems began to take shape at the end of the 20th century and the beginning of the 21 st century and was called the "postmodern period" or "digital era". Major changes in this period of political communication development have occurred both in technology, consumer behavior of voters, and in communication strategies.

The main features of the postmodern era of political communication were presented by Darrent Lilleker (2006), among which we can mention:

(1) Coordinated national campaigns that are operationalized in a decentralized form within local campaigns. In more and more countries, insists on the power of persuasion of local political actors that "personalize" the social message, the central political message coordinated by a national campaign team. Thus, it was found that a political communication in the form of a network, ie the existence of opinion leaders (whether they are political actors, whether they are journalists or representatives of civil society) at each node of the network to influence the social groups belonging to that networking is more effective than a centralized model of political communication where central organizations do not know the particularities, needs, political or civic culture of each social group. 
(2) Narrowcasting. This principle involves direct communication to key groups or segments within the electorate. In the early stages of postmodern communication, politicians used magazines, newspapers or niche TV channels to reach the target audience. With the development of Internet communication, more sophisticated methods have been used to reach the target audience, namely through emails, newsletters, or, more recently, on online social networking.

(3) The Permanent Campaign - refers to the use of state institutions by elected politicians in order to maintain their popular support. The term was first used in 1976 by Pat Cadell, former US President Jimmy Carter's advisor, who advised Carter to continue the campaign even if the elections were completed. Such practices have been reported by various journalists, including Sidney Blumenthal, and former US presidents, Reagan and Clinton. So, it has been found that the communication process plays an important role in governance, like fiscal policies do, and permanent campaigns have been incorporated as an indispensable feature in modern governments.

All these distinct characteristics of the earlier epochs have led to major changes in political communication systems, which many authors have called "americanization", "standardization" or "professionalization" of the political communication. This stage of development has been differentiated from the other stages by borrowing more aspects of commercial communication, such as political marketing, strategic management, and in this context, the voter-audience was likened by Cees Halelink (2007) to a "political consumer".

Another feature of this era was the decline of political parties in their social base as the number of people wishing to join a political party diminished considerably. This has had major repercussions on the electoral behavior of citizens, the loyal and disciplined voter of a party (as we know it in the first stages of the development of political communication) has become pragmatic without solid doctrinal beliefs, willing to change the option of voting according to certain instincts or according to its sensitivity to the persuasion of political actors or the media.

The political communication systems and mechanisms of this period have become much more complex than the previous phases, and British researchers Jay Blumler and Dennis Kavanagh (1999) have identified three trends that have reformulated the whole of the mass communication process: (1) professionalizing political communication, 2) increased competition pressure, (3) the development of an anti-elitist current of political communication, the emergence of populism and the diversification of forms and means of communication. 


\section{The fourth phase of the evolution of political communication systems: new media era}

After 1990, for many other democratic countries and after 2000, for other totalitarian countries, political communication has undergone a strong transformation into its three points: (1) changing the communication channel and its characteristics far different from classical means, (2) related to the content of the message and the political discourse and, perhaps, the most important aspect (3) the public's ability to actively participate in government acts or protest actions challenging government acts.

This global process of transformation of political communication is based on the liberalization of contemporary society, especially the liberalization of the media, even in countries with a totalitarian regime, the reduction of government control and, of course, the spread and development of new mass-communication technologies. In the context of intensifying and unleashing a new communicative power competing with the traditional media power, these processes have led to the emergence of a series of general trends at national policy level, about which Sandra Moog and Jeffrey Sluyter-Beltrao (2001) say they have "altered the ways in which social actors and issues of public interest are represented in the media, the ways in which political actors try to communicate with each other and with potential supporters and, as a result, even the forms of such organizations, such as political parties, interest groups and movements social, which have shaped, in their turn, the modern political processes" (Moog, Sluyter-Beltrao, 2001).

In other words, the new models of political communication developed by the characteristics of the new channels of mass communication have intensified the active participation both from the social actors and politicians, especially from the electorate, but the quality of the speech has decreased. More than the quality of the discourse, the themes discussed have touched on issues that are not related to the public interest, but rather to the personal life of politicians.

In this context, the amount of discourse greatly depends, which in turn generates commitment from the masses, and the quality of speech is no longer a strong point. On the other hand, there are voices, among which we can remember Andrew Wernick (2001) who states that the decline in the quality of political discourse must not necessarily be attributed to the new media age as they are only a continuation of marketing processes and improved techniques political marketing that has been taking place over the past two decades. Moreover, Wernick argues that "promotionalism [...] is, in essence, little more than the natural evolution of the intrinsic competitive processes in mass electoral democracy".

The first step in developing communication strategies tailored to the new media was the understanding that the type of relationship with the electorate has fundamentally changed. If before the Internet the political actor had control over the information and sent a message unidirectionally - from 
the television platforms to an electoral rally - in the Internet era, it is no longer the only transmitter that sends messages to a large mass of people. The new media have developed a new concept of mass communication, called "many-to-many".

In the era of digitization, excluding the period in which the New Media emerged and developed, political communication functioned on two dimensions / directions: one-dimensional and two-dimensional. When we talk about unidimensional communication, we are talking about that simple process through which the message arrives in one direction to the recipient. The onedimensional communication can be included in the mass communication field and usually involves a very well-controlled and strategically built message that is to be transmitted to a large audience. In the case of political communication through the one-dimensional model, we refer to that simple transmission of the message, in one step, from a politician or a candidate to citizens / voters. Applying this model to the system developed by the Internet then refers to sending emails to the voters or browsing the web pages by citizens because, in this latter example, the message comes directly from the politician.

Two-dimensional communication, also called interpersonal, requires a bivalent relationship in which both the emitter and the receiver of the message are actively involved. In the category of twodimensional communication we can include the face-to-face conversation of individuals because both entities exchange information, becoming both communicator and receiver. Applied in online political communication, this model involves integrating action tools and facilitating meaningful feedback and provides citizens with the opportunity to respond to candidates through a comment on their personal blog on the party's website or directly on the Facebook page.

With the emergence and development of New Media, a new three-dimensional communication system has been developed. In the present, communication flows to and from the campaign as well as in any other direction between and among the voters. This pattern occurs between and among voters who have the ability to connect with each other much easier thanks to various new media, and candidates have to consider and treat voters and supporters as strategic partners because this system allows a person to stop certain movements, which the political actors, by themselves, could not undertake. With the emergence and development of this new model of political communication, the public, formerly known as the "audience", is no longer a simple message receiver, they are no longer captives of the simplistic unidirectional, source-message-receiver communication model developed in 1963 by Weaver and Shannon, but is a key factor in disseminating the political message to other social groups that he controls more effectively than the political actor.

The Internet has led to another level of asynchronous and synchronous communication, even if the foundations remained the same. While the type of synchronous communication refers to real-time or instance communication, asynchronous communication refers to the non-Symfonic communication 
process with delayed or even non-existent feedback. The synchronicity of online communication has revolutionized political communication, generating a much greater degree of interaction and more and deeper connections between voters and between voters and politicians. This type of communication has developed the multidimensionality of communication and has enabled voters from other parts of the country or other countries to debate real-time issues of public interest or electoral messages in real time.

\section{References}

[1] Blumler, J., Kavanagh, D. (1999). The Third Age of Political Communication: Influences and Featured. Political Communication, 16(3). London: Routledge

[2] Lilleker, D. (2006). Key concepts in political communication. London: SAGE Publications Ltd., 32

[3] Hamelink, C. (2007). The Professionalization of Political Communication: Democracy at Stake?. The Professionalisation of Political Communication, vol. 3. Intellect Books, 182

[4] Moog, S., Sluyter-Beltrao, J. (2001). The Transformation of Political Communication?. New Media \& Politics. London: Sage, 30. 